\title{
Exocytosis and endocytosis in neuroendocrine cells: inseparable membranes!
}

\section{Sébastien Houy, Pauline Croisé, Olga Gubar, Sylvette Chasserot-Golaz, Petra Tryoen-Tóth, Yannick Bailly, Stéphane Ory, Marie-France Bader and Stéphane Gasman*}

Institut des Neurosciences Cellulaires et Intégratives (INCI), Centre National de la Recherche Scientifique (CNRS UPR 3212), Université de Strasbourg, Strasbourg, France

\section{Edited by:}

Rafael Vazquez-Martinez, University of Cordoba, Spain

Reviewed by:

Silvio O. Rizzoli, European

Neuroscience Institute Göttingen.

Germany

Corey Smith, Case Western Reserve University, USA

\section{*Correspondence.}

Stéphane Gasman, Institut des

Neurosciences Cellulaires et

Intégratives (INCl), Centre National de

la Recherche Scientifique (CNRS UPR

3212), Université de Strasbourg, 5 rue

Blaise Pascal, Strasbourg 67084,

France

e-mail: gasman@inci-cnrs.unistra.fr
Although much has been learned concerning the mechanisms of secretory vesicle formation and fusion at donor and acceptor membrane compartments, relatively little attention has been paid toward understanding how cells maintain a homeostatic membrane balance through vesicular trafficking. In neurons and neuroendocrine cells, release of neurotransmitters, neuropeptides, and hormones occurs through calcium-regulated exocytosis at the plasma membrane. To allow recycling of secretory vesicle components and to preserve organelles integrity, cells must initiate and regulate compensatory membrane uptake. This review relates the fate of secretory granule membranes after full fusion exocytosis in neuroendocrine cells. In particular, we focus on the potential role of lipids in preserving and sorting secretory granule membranes after exocytosis and we discuss the potential mechanisms of membrane retrieval.

Keywords: exocytosis, compensatory endocytosis, membrane lipids, neuroendocrine cells, chromaffin cells

\section{INTRODUCTION}

Mammalian cells exhibit complex and dynamic patterns of intracellular membrane traffic between various organelles. Although much has been learned concerning the mechanisms of vesicle transport and vesicle fusion at donor and acceptor compartments, relatively little attention has been paid to understanding how organelle homeostasis is maintained. This aspect is particularly important in neurosecretory cells in which intense membrane trafficking and mixing occurs between secretory vesicles and the plasma membrane during secretion of various transmitters, peptides, and hormones. Calcium-regulated exocytosis, i.e., fusion of secretory vesicles with the plasma membrane results in the merging of these two membrane compartments, hence triggering an increase in plasma membrane surface and loss of identity. As a consequence, exocytosis must be coupled to a compensatory endocytotic process allowing the plasma membrane to recover its integrity and the granule membrane to be recycled. In neurons, molecular mechanisms of synaptic vesicle recycling and coupling with exocytosis have been intensively studied, but is still debated [for reviews see (1-3)]. However, the equivalent process for large dense core granules in neuroendocrine cells remains largely unexplored.

In neuroendocrine cells, secretion can occur through different modes of exocytosis depending on the physiological demand (see Figure 1 for details). The "kiss-and-run" mode allows only the release of catecholamines and other small molecules through a narrow fusion pore $(4,5)$. During "cavicapture" (granule cavity capture) mode, expansion of the fusion pore triggers partial release of the small proteins (6-9). During kiss-and-run and cavicapture processes, the granule shape remains almost intact, whereas during "full collapse" or "full fusion" exocytosis, granules lose their round shape, flatten out in the plane of the plasma membrane leading to the merging of these two compartments and the complete release of the granular content (10-12). Whereas the molecular mechanisms of the various exocytotic modes (secretory vesicle recruitment, docking, priming, and fusion processes) have been largely explored, how granule and plasma membranes maintain their composition and recover their integrity after full fusion exocytosis is poorly known. Two types of retrieval have been described after full fusion exocytosis: clathrin-mediated endocytosis and bulk endocytosis. Bulk endocytosis occurs during elevated secretory activity when clathrin-mediated endocytosis is unable to fully compensate the large increase in membrane surface. To rapidly reverse this excess of plasma membrane, bulk endocytosis internalizes large invaginations of plasma membrane, which then form endosomal-like compartments. Bulk endocytosis has been described in several reviews $(13,14)$. Here, we focus on potential mechanisms that allow neuroendocrine cells to compensate full fusion exocytosis of large dense core vesicles through clathrin-mediated endocytosis.

\section{THE FATE OF THE SECRETORY GRANULE MEMBRANE AFTER FUSION}

For a long time, it was believed that after full fusion exocytosis vesicular components diffuse into the plasma membrane and are subsequently randomly internalized. This model implies that both the secretory vesicle and plasma membranes lose their identities and that exocytosis is not directly coupled to endocytosis. In contradiction with this model, synaptic activity in neurons results neither in the overall dispersion of vesicle components in the plasma membrane nor in the enrichment of 


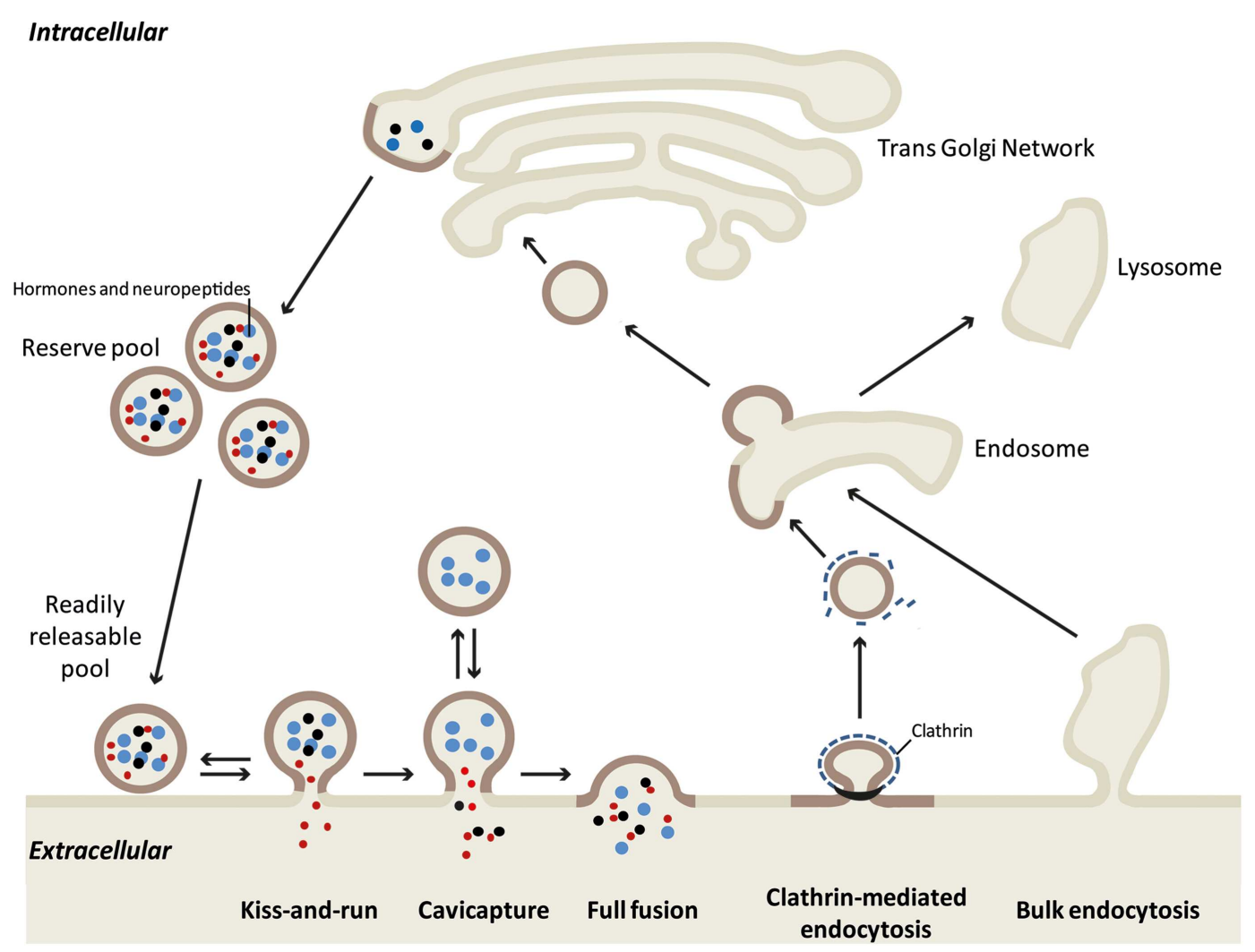

FIGURE 1 | Different models of exo-endocytosis coupling in neuroendocrine cells. Hormone sorting and large dense core granule biogenesis occurs at the trans-Golgi network. Mature granules either constitute the reserve pool or are recruited to the plasma membrane as a readily releasable pool. Large proteins (blue dots), small neuropeptides (black dots), and small molecules like catecholamines (red dots) can be released differentially according to the exo-endocytosis mode. During "kiss-and-run" mode, only small molecules are released through a narrow fusion pore,

whereas cavicapture (granule cavity capture) allow the partial release of small neuropeptides (7). Note that for these two modes, retrieval of intact granules is easily conceived as the granule shape remains almost intact. During full fusion exocytosis, the intra-granular contents are all released and the granule membrane collapses into the plasma membrane. This membrane incorporation is compensated by clathrin-mediated endocytosis that specifically retrieves granule membrane piece by piece [see Figure 2 and (19)]. After uncoating, the endocytic granule membrane reaches early endosome where granule components remain clustered (12), before being re-maturated the Golgi network. During intense exocytotic activity, bulk endocytosis supports clathrin-mediated endocytosis by internalizing large plasma membrane invaginations that most likely follow the lysosomal degradation pathway. plasma membrane components in synaptic vesicles (2). Similarly, despite full fusion exocytosis in neuroendocrine cells, granules, and plasma membranes seem to maintain their specific protein composition.

Early evidence for exo-endocytosis coupling came from morphological studies in the 80 s suggesting that large dense core granule membrane-bound components could be retrieved after exocytosis $(10,15)$. At the same time, Geisow and co-workers observed an important increase in the number of coated pits containing secretory granule components in secretagogue-stimulated chromaffin cells (16). Later on patch-clamp and imaging studies suggested a fast temporal coupling between exocytosis and endocytosis processes $(17,18)$.

Using electron microscopy of cultured chromaffin cells, our group has recently described clustering of secretory granule proteins on the plasma membrane after full fusion exocytosis, arguing against the idea that granule components are dispersed in the plasma membrane (12). The group of Holz recently confirmed that chromaffin granule markers remain associated after fusion
(19). Additionally, we have shown that these granule-bound proteins are subsequently internalized through vesicles devoid of plasma membrane makers (12). In other words, granule membranes are maintained together as "microdomains" after exocytosis and are subsequently recaptured without intermixing with the plasma membrane. How do neuroendocrine cells preserve granule membrane integrity after full collapse and precisely sort granule membrane lipids and associated proteins?

\section{LIPIDS AS CENTRAL ORGANIZERS OF EXO-ENDOCYTOSIS COUPLING?}

CREATING MEMBRANE DOMAINS TO PRESERVE GRANULE IDENTITY

The preservation of secretory granule identity after fusion with the plasma membrane implies that both proteins and lipids do not diffuse in the plasma membrane. Lateral segregation of membrane lipids would in this case represent an obvious sorting mechanism. Interestingly, we and others have shown that exocytosis requires several types of lipid remodeling processes (described in the present "Research Topic" by Amar et al. (28)). Some of 
these processes might contribute to prevent granular component from diffusing. For instance, secretagogue-evoked stimulation of chromaffin cells triggers the formation of lipid raft microdomains at the plasma membrane enriched in ganglioside GM1, cholesterol, and phosphatidylinositol 4,5 bisphosphate $\left[\mathrm{PI}(4,5) \mathrm{P}_{2}\right]$. Such lipid rafts correspond to membrane areas stabilized by the presence of cholesterol within a liquid-ordered phase in which lateral diffusion of proteins and lipids is limited, resulting in the clustering of specific components (20). In neuroendocrine and various other secretory cells, lipid raft formation is necessary for the spatial organization of the exocytotic machinery including SNARE proteins (21-23). As a consequence, it is tempting to imagine that this lipid confinement at the exocytotic sites would help to prevent granular lipids and proteins from diffusing after secretory granules fusion with the plasma membrane.

Of particular interest, the formation of membrane domains corresponding to exocytotic sites is regulated by annexin-A2 (21, 24), a calcium- and phospholipid-binding protein involved in both exo- and endocytosis (25). Annexin-A2 has been described on clathrin-coated vesicles in the adrenal gland (26). The protein displays two typical YXX $\varnothing$ endocytic motifs allowing its interaction with the $\mu 2$-subunit of the AP-2 complex that triggers clathrin recruitment (27). Therefore, annexin-A2 constitutes a strong candidate to participate in the coupling of secretory granule exocytosis with the subsequent compensatory endocytosis.

\section{PI(4,5)P2: ORCHESTRATING EXO-ENDOCYTOSIS COUPLING}

Phosphatidylinositol 4,5 bisphosphate $\left[\mathrm{PI}(4,5) \mathrm{P}_{2}\right]$ has been largely described as an important regulator in exocytosis $(28,29)$ but it is also known to recruit and regulate multiple components involved in clathrin-mediated endocytosis. Therefore, the $\mathrm{PI}(4,5) \mathrm{P}_{2}$-enriched membrane microdomains where exocytosis occurs is likely to constitute preferential spots for endocytosis, a perfect way to couple these two processes. For example, interaction of the adaptor protein AP-2 with YXX $\varnothing$ endocytic motifs is driven by its interaction with $\mathrm{PI}(4,5) \mathrm{P}_{2}(30)$. Local $\mathrm{PI}(4,5) \mathrm{P}_{2}$ concentration regulates the membrane binding and deformation capacity of proteins containing Bin/amphiphysin/Rvs (BAR) domains including endophilin, syndapin, and amphiphysin, three membrane-deforming scaffold proteins that have been implicated in endocytotic processes $(31,32)$. Interestingly, it has been proposed that BAR domains participate in the fission of budding vesicles by synergistically cooperating with dynamin, a GTPase also sensitive to $\mathrm{PI}(4,5) \mathrm{P}_{2}(33)$. Moreover, in collaboration with the group of Dr. Cardenas, we have recently demonstrated that dynamin-2 controls both exocytosis, by regulating fusion pore expansion, and the subsequent endocytosis of secretory granules in chromaffin cells (34). Finally, $\mathrm{PI}(4,5) \mathrm{P}_{2}$ also regulates the dynamics of actin filaments, which are believed to limit plasma membrane protein diffusion and/or to directly participate in endocytosis $(35,36)$. Accordingly, we have previously demonstrated that actin filaments are formed at a post-docking step of exocytosis (37) and disruption of actin filament organization inhibits compensatory endocytosis after full fusion. These data suggest that actin remodeling is also implicated in the process of internalization perse (12).

\section{PHOSPHOLIPID SCRAMBLING: A SIGNAL TO TRIGGER COMPENSATORY ENDOCYTOSIS?}

One key feature of cell membranes is the asymmetric distribution of phospholipids between the leaflets. In the plasma membrane, phosphatidylserine (PS) and phosphatidylethanolamine (PE) reside in the inner cytoplasmic leaflet while phosphatidylcholine and sphingomyelin are located in the outer leaflet (38). In non-apoptotic cells, several biological functions are accompanied by a disruption of this phospholipid asymmetry resulting in the externalization of PS in the outer leaflet of the plasma membrane (39). This phenomenon has been observed during regulated exocytosis in mast cells (40), nerve terminals (41), and the neuroendocrine PC12 and chromaffin cells (12, 42, 43). More recently, we have shown that PS externalization occurs in specific domains at the frontier between the fused granule membrane and the plasma membrane and is triggered by the calcium-sensitive phospholipid scramblase-1 (PLSCR1). Interestingly, in chromaffin cells cultured from PLSCR1 knock-out mice, surface exposure of PS is not involved in exocytosis, but is required for granule membrane compensatory endocytosis (44).

To date no current evidence is available to explain the mechanism by which PS externalization is linked to compensatory endocytosis. However, two scenarios are possible. Firstly, as loss of phospholipid asymmetry can modify the mechanical stability of membranes (45), this might facilitates local reorganization of lipids surrounding the granule membrane transiently inserted within the plasma membrane and preserve the integrity of the granule membrane. Secondly, as an anionic phospholipid, PS confers negative charges and directly binds various proteins involved in exocytosis like annexin-A2, rabphilin, DOC 2, or synaptotagmin (46). PLSCR1-induced local decrease in PS concentration in the inner leaflet of the plasma membrane could therefore represent a signal to switch from exocytosis to endocytosis, thereby permitting the release of exocytotic components and/or the recruitment of the endocytic machinery.

However, whether externalization of PS simply reflects the loss of PS asymmetry or reveals more profound lipid reorganization is basically unknown and requires further investigation.

\section{HOW TO RECAPTURE A LARGE DENSE CORE VESICLE?}

In chromaffin cells, we have found that clathrin is rapidly recruited to the granule membrane right after merging with the plasma membrane and that knocking-down clathrin expression drastically blocks compensatory endocytosis (12). The clathrin dependency of large dense core granule endocytosis raises the question of the mechanism by which a granule displaying a mean diameter of about $250 \mathrm{~nm}$ may be recaptured by a clathrin coat? Energetic constraints indicate that in vitro clathrin baskets assemble with a mean diameter of $100 \mathrm{~nm}$ or even less $(80 \mathrm{~nm})$ in the presence of adaptor proteins (47). In INS-1 insulinoma cells for example, the mean diameter of secretory granule ranges from 110 to $170 \mathrm{~nm}$ but the endocytotic events detected by capacitance measurements correspond to vesicles of $70 \mathrm{~nm}$ diameter (48). In mouse chromaffin cells, the average size of endocytic vesicles calculated from endocytic capacitance step sizes is $122 \mathrm{~nm}$ (49). Accordingly, recent electron microscopy experiments performed on chromaffin cells demonstrated that clathrin-coated vesicles size increases 


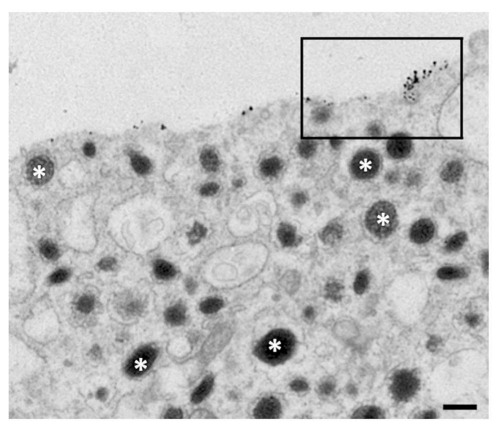

FIGURE 2 | Ultrastructural observation of budding vesicle from exocytotic spots in stimulated chromaffin cells. To stain specifically the granule membrane fused with plasma membrane, stimulated cells are incubated in the presence of antibodies raised against the luminal region of dopamine-beta hydroxylase (DBH), a transmembrane marker of

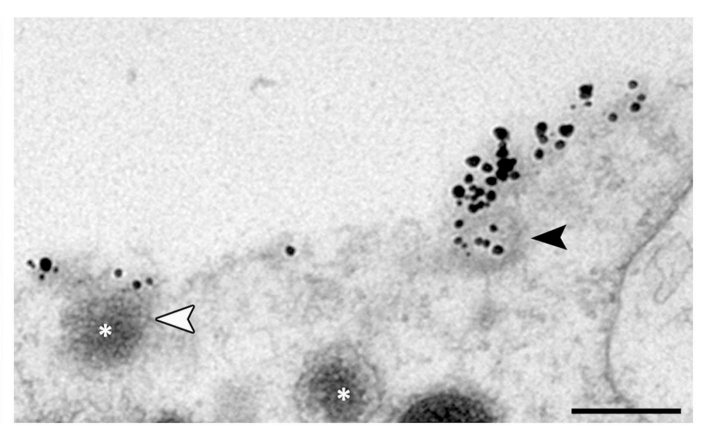

secretory granules (asterisks). Note that small vesicles budding can be observed from the DBH antibodies clusters (black arrowhead in enlarged view) suggesting a partial recapture of the granule membrane. The white arrowhead shows a granule fusing with the plasma membrane. Bar $=100 \mathrm{~nm}$. upon potassium stimulation (mean diameter of $87 \mathrm{~nm}$ ) compared to resting cells (19). Altogether, these observations tend to demonstrate that large granule membranes may be recaptured as small pieces rather than a whole. Indeed, direct observations of the internalization of fused granule membranes allowed us to reveal early endocytotic events corresponding to $50-80 \mathrm{~nm}$ coated vesicles budding from granular membrane-bound proteins clusters (Figure 2).

\section{ENDOCYTIC PATHWAY}

The intracellular route followed by the post-exocytotic internalized granules has not been fully characterized. The main difference with synaptic vesicle recycling is that, to be reused, large dense core granules need to be reloaded with matrix proteins, which most likely implies a re-maturation process involving the Golgi apparatus. The transient accessibility of granule-bound proteins at the cell surface during full fusion exocytosis has been exploited to label and follow post-fusion granules with specific antibodies or biotinylation. This approach was widely used in the 80 s in order to demonstrate that granule-bound proteins transit through the Golgi region before being recycled in newly mature granules $(10,15,50,51)$. Alternatively, granule markers have been proposed to be degraded through a lysosomal pathway $(52,53)$. Both recycling and degradation pathways coexist and their proportion may depend on cell secretory activity. The recycling pathway leading to releasable granules is more predominant upon mild stimulation whereas above a certain threshold of membrane incorporation during intense exocytotic activity, the occurrence of bulk endocytosis will lead to the degradation of the internalized membrane $(54,55)$. Altogether, these data do not provide any information concerning the immediate fate of internalized granule membrane. Our group has observed that internalized granule-bound markers rapidly co-localize with the early endosomal marker EEA1, suggesting that chromaffin granule components might be retrieved through early endosomes after regulated exocytosis (12). Since clathrin is likely to retrieve the collapsed granule membrane as pieces and not as a whole, the early endosomes might constitute a transient sorting station that would sort the retrieved pieces to reconstitute a functional granule prior to entering the retrograde transport pathway to the TGN. Accordingly, we have observed budding of the immunogold-labeled DBH clusters present on endosomes (unpublished data).

\section{CONCLUSION}

New evidence is now emerging to support the idea that, in neuroendocrine cells but also in neurons, vesicle/granule membranes do not intermix with the plasma membrane following full fusion exocytosis $(56,57)$. Compensation of membrane incorporation by endocytosis is a critical process and selective recapture of secretory organelles is required to maintain cellular homeostasis. Resolving the mechanisms that specifically preserve the granule membrane platform and retain granular components together after its incorporation in the plasma membrane to is the next challenging question to answer. Highly resolutive biophotonic approaches are now required to precisely investigate the dynamic behavior of secretory granules merged with the plasma membrane during and after exocytosis. Lipids clearly play a central role in this process, but attention should also be given to bi-functional proteins regulating both exo- and endocytosis, in particular annexin, synaptotagmin, and BAR domain-containing proteins.

\section{ACKNOWLEDGMENTS}

We wish to thank Dr. Nancy Grant for critical reading of the manuscript. We thank V. Calco and A. M. Haeberlé for setting up preliminary experiments and T. Thahouly for technical assistance. Part of the work from our group discussed in this review was supported by various grant to Stéphane Gasman: ANR grant (ANR-07-JCJC-088-01), “Association pour la Recherche sur le Cancer" grant (ARC \#1055), and EMMA service (under the EU contract Grant Agreement Number 227490) of the EC FP7 Capacities Specific Programme. We acknowledge the Plateforme "Imagerie in vitro" (NeuroPôle; Strasbourg). Especially A. M. Haeberlé and V. Demais for their excellent technical assistance in electron microscopy. 


\section{REFERENCES}

1. Gundelfinger

ED, Kessels MM, Qualmann B. Temporal and spatial coordination of exocytosis and endocytosis. Nat Rev Mol Cell Biol (2003) 4:127-39. doi:10.1038/ nrm1016

2. Rizzoli SO, Jahn R. Kissand-run, collapse and 'readily retrievable' vesicles. Traffic (2007) 8:1137-44. doi:10.1111/j. 1600-0854.2007.00614.x

3. Haucke V, Neher E, Sigrist SJ. Protein scaffolds in the coupling of synaptic exocytosis and endocytosis. Nat $\mathrm{Rev} \mathrm{Neu}$ rosci (2011) 12:127-38. doi:10.1038/nrn2948

4. Henkel AW, Kang G, Kornhuber J. A common molecular machinery for exocytosis and the 'kiss-and-run' mechanism in chromaffin cells is controlled by phosphorylation. J Cell Sci (2001) 114: 4613-20.

5. Hanna ST, Pigeau GM, Galvanovskis J, Clark A, Rorsman P, Macdonald PE. Kiss-and-run exocytosis and fusion pores of secretory vesicles in human beta-cells. Pflugers Arch (2009) 457:1343-50. doi:10.1007/s00424008-0588-0

6. Taraska JW, Perrais D, OharaImaizumi $M$, Nagamatsu $S$, Almers W. Secretory granules are recaptured largely intact after stimulated exocytosis in cultured endocrine cells. Proc Natl Acad Sci U $S \quad A \quad(2003) \quad$ 100:2070-5. doi:10.1073/pnas.0337526100

7. Perrais D, Kleppe IC, Taraska JW, Almers W. Recapture after exocytosis causes differential retention of protein in granules of bovine chromaffin cells. J Physiol (2004) 560:413-28. doi:10.1113/ jphysiol.2004.064410

8. Fulop T, Radabaugh S, Smith C. Activity-dependent differential transmitter release in mouse adrenal chromaffin cells. J Neurosci (2005) 25:7324-32. doi:10.1523/ JNEUROSCI.2042-05.2005

9. Llobet $\mathrm{A}, \mathrm{Wu} \mathrm{M}$, Lagnado L. The mouth of a dense-core vesicle opens and closes in a concerted action regulated by calcium and amphiphysin. J Cell Biol (2008) 182:1017-28. doi: $10.1083 /$ jcb. 200807034

10. Patzak A, Winkler H. Exocytotic exposure and recycling of membrane antigens of chromaffin granules: ultrastructural evaluation after immunolabeling. J Cell Biol
(1986) 102:510-5. doi:10.1083/jcb. 102.2.510

11. Wick PF, Trenkle JM, Holz RW. Punctate appearance of dopaminebeta-hydroxylase on the chromaffin cell surface reflects the fusion of individual chromaffin granules upon exocytosis. Neuroscience (1997) 80:847-60. doi:10. 1016/S0306-4522(97)00062-6

12. Ceridono M, Ory S, Momboisse F, Chasserot-Golaz S, Houy S, Calco $\mathrm{V}$, et al. Selective recapture of secretory granule components after full collapse exocytosis in neuroendocrine chromaffin cells. Traffic (2011) 12:72-88. doi:10.1111/j. 1600-0854.2010.01125.x

13. Clayton EL, Cousin MA. The molecular physiology of activitydependent bulk endocytosis of synaptic vesicles. $J$ Neurochem (2009) 111:901-14. doi:10.1111/j. 1471-4159.2009.06384.x

14. Cardenas AM, Marengo FD. Rapid endocytosis and vesicle recycling in neuroendocrine cells. Cell Mol Neurobiol (2010) 30:1365-70. doi:10. 1007/s10571-010-9579-8

15. Patzak A, Bock G, Fischer-Colbrie R, Schauenstein K, Schmidt W, Lingg G, et al. Exocytotic exposure and retrieval of membrane antigens of chromaffin granules: quantitative evaluation of immunofluorescence on the surface of chromaffin cells. J Cell Biol (1984) 98:1817-24. doi:10.1083/jcb.98.5 . 1817

16. Geisow MJ, Childs J, Burgoyne RD. Cholinergic stimulation of chromaffin cells induces rapid coating of the plasma membrane. Eur J Cell Biol (1985) 38:51-6.

17. Smith C, Neher E. Multiple forms of endocytosis in bovine adrenal chromaffin cells. J Cell Biol (1997) 139:885-94. doi:10.1083/jcb.139.4. 885

18. Tsuboi T, Zhao C, Terakawa S, Rutter GA. Simultaneous evanescent wave imaging of insulin vesicle membrane and cargo during a single exocytotic event. Curr Biol (2000) 10:1307-10. doi:10. 1016/S0960-9822(00)00756-9

19. Bittner MA, Aikman RL, Holz RW. A nibbling mechanism for clathrinmediated retrieval of secretory granule membrane after exocytosis. J Biol Chem (2013) 288:9177-88. doi:10.1074/jbc.M113.450361

20. Lingwood D, Simons K. Lipid rafts as a membrane-organizing principle. Science (2010) 327:46-50. doi: 10.1126/science.1174621

21. Chasserot-Golaz S, Vitale N, Umbrecht-Jenck E, Knight D,
Gerke V, Bader MF. Annexin 2 promotes the formation of lipid microdomains required for calcium-regulated exocytosis of dense-core vesicles. Mo Biol Cell (2005) 16:1108-19. doi:10.1091/mbc.E04-07-0627

22. Salaun C, Gould GW, Chamberlain LH. Lipid raft association of SNARE proteins regulates exocytosis in PC12 cells. J Biol Chem (2005) 280:19449-53. doi:10.1074/ jbc.M501923200

23. Puri N, Roche PA. Ternary SNARE complexes are enriched in lipid rafts during mast cell exocytosis. Traffic (2006) 7:1482-94. doi:10.1111/j. 1600-0854.2006.00490.x

24. Umbrecht-Jenck E, Demais V, Calco V, Bailly Y, Bader MF, ChasserotGolaz S. S100A10-mediated translocation of annexin-A2 to SNARE proteins in adrenergic chromaffin cells undergoing exocytosis. Traffic (2010) 11:958-71. doi: 10.1111/j.1600-0854.2010.01065.x

25. Futter CE, White IJ. Annexins and endocytosis. Traffic (2007) 8:951-8. doi:10.1111/j.1600-0854. 2007.00590.x

26. Turpin E, Russo-Marie F, Dubois T, De Paillerets C, Alfsen A, Bomsel M. In adrenocortical tissue, annexins II and VI are attached to clathrin coated vesicles in a calcium-independent manner. Biochim Biophys Acta (1998) 1402 115-30. doi:10.1016/S01674889(97)00151- 1

27. Creutz CE, Snyder SL. Interactions of annexins with the mu subunits of the clathrin assembly proteins. Biochemistry (2005) 44:13795-806. doi:10.1021/bi051160w

28. Ammar MR, Kassas N, ChasserotGolaz S, Bader M-F, Vitale N. Lipids in regulated exocytosis: what are they doing? Front Endocrino (2013) 4:125. doi:10.3389/fendo. 2013.00125

29. Chasserot-Golaz S, Coorssen JR, Meunier FA, Vitale N. Lipid dynamics in exocytosis. Cell $\mathrm{Mol} \mathrm{Neu}$ robiol (2010) 30:1335-42. doi:10 1007/s10571-010-9577-x

30. Jackson LP, Kelly BT, Mccoy AJ, Gaffry T, James LC, Collins BM, et al. A large-scale conformational change couples membrane recruitment to cargo binding in the AP2 clathrin adaptor complex. Cell (2010) 141:1220-9. doi:10.1016/j. cell.2010.05.006

31. Rao Y, Haucke V. Membrane shaping by the Bin/amphiphysin/Rvs (BAR) domain protein superfamily. Cell Mol Life Sci (2011) 68:3983-93. doi:10.1007/s00018-011-0768-5
32. Yoon Y, Zhang X, Cho W. Phosphatidylinositol 4,5-bisphosphate (PtdIns(4,5)P2) specifically induces membrane penetration and deformation by Bin/amphiphysin/Rvs (BAR) domains. J Biol Chem (2012) 287:34078-90. doi:10.1074/jbc.M112.372789

33. Meinecke M, Boucrot E, Camdere G, Hon WC, Mittal R, Mcmahon HT. Cooperative recruitment of dynamin and BIN/amphiphysin/Rvs (BAR) domain-containing proteins leads to GTP-dependent membrane scission. J Biol Chem (2013) 288:6651-61. doi:10.1074/jbc.M112.444869

34. González-Jamett AM, Momboisse F Guerra MJ, Ory S, Báez-Matus X, Barraza N, et al. Dynamin-2 regulates fusion pore expansion and quantal release through a mechanism that involves actin dynamics in neuroendocrine chromaffin cells. PLoS One (2013) 8:e70638. doi:10. 1371/journal.pone.0070638

35. Winckler B, Forscher P, Mellman I. A diffusion barrier maintains distribution of membrane proteins in polarized neurons. Nature (1999) 397:698-701. doi:10.1038/17806

36. Mooren OL, Galletta BJ, Cooper JA. Roles for actin assembly in endocytosis. Аnnu Rev Biochem (2012) 81:661-86. doi:10.1146/ annurev-biochem-060910-094416

37. Gasman S, Chasserot-Golaz S, Malacombe M, Way M, Bader MF. Regulated exocytosis in neuroendocrine cells: a role for subplasmalemmal $\quad \mathrm{Cdc} 42 / \mathrm{N}$ WASP-induced actin filaments. Mol Biol Cell (2004) 15:520-31. doi:10.1091/mbc.E03-06-0402

38. van Meer G, Voelker DR, Feigenson GW. Membrane lipids: where they are and how they behave. Nat Rev Mol Cell Biol (2008) 9:112-24. doi:10.1038/nrm2330

39. Ikeda M, Kihara A, Igarashi Y. Lipid asymmetry of the eukaryotic plasma membrane: functions and related enzymes. Biol Pharm Bull (2006) 29:1542-6. doi:10.1248/bpb. 29.1542

40. Demo SD, Masuda E, Rossi AB, Throndset BT, Gerard AL, Chan EH, et al. Quantitative measurement of mast cell degranulation using a novel flow cytometric annexin- $\mathrm{V}$ binding assay. Cytometry (1999) 36:340-8. doi:10.1002/(SICI) 1097 0320(19990801)36:4<340::AIDCYTO9>3.0.CO;2-C

41. Lee D, Hirashima N, Kirino Y. Rapid transbilayer phospholipid redistribution associated with exocytotic 
release of neurotransmitters from cholinergic nerve terminals isolated from electric ray Narke japonica. Neurosci Lett (2000) 291: 21-4. doi:10.1016/S0304-3940(00) 01365-3

42. Vitale N, Caumont AS, ChasserotGolaz S, Du G, Wu S, Sciorra VA, et al. Phospholipase D1: a key factor for the exocytotic machinery in neuroendocrine cells. EMBO J (2001) 20:2424-34. doi:10.1093/emboj/20. 10.2424

43. Malacombe M, Ceridono M, Calco V, Chasserot-Golaz S, Mcpherson PS, Bader MF, et al. Intersectin1L nucleotide exchange factor regulates secretory granule exocytosis by activating Cdc 42 . EMBOJ (2006) 25:3494-503. doi:10.1038/sj.emboj. 7601247

44. Ory S, Ceridono M, Momboisse F, Houy S, Chasserot-Golaz S, Heintz D, et al. Phospholipid scramblase-1-induced lipid reorganization regulates compensatory endocytosis in neuroendocrine cells. J Neurosci (2013) 33:3545-56. doi:10.1523/ JNEUROSCI.3654-12.2013

45. Manno S, Takakuwa Y, Mohandas $\mathrm{N}$. Identification of a functional role for lipid asymmetry in biological membranes: phosphatidylserineskeletal protein interactions modulate membrane stability.
Proc Natl Acad Sci U S A (2002) 99:1943-8. doi:10.1073/pnas. 042688399

46. Stace CL, Ktistakis NT. Phosphatidic acid- and phosphatidylserinebinding proteins. Biochim Biophys Acta (2006) 1761:913-26. doi:10. 1016/j.bbalip.2006.03.006

47. Nossal R. Energetics of clathrin basket assembly. Traffic (2001) 2:138-47. doi:10.1034/j.1600-0854. 2001.020208.x

48. MacDonald PE, Eliasson L, Rorsman P. Calcium increases endocytotic vesicle size and accelerates membrane fission in insulinsecreting INS-1 cells. J Cell Sci (2005) 118:5911-20. doi:10.1242/ jcs.02685

49. Yao LH, Rao Y, Varga K, Wang CY, Xiao $P$, Lindau $M$, et al. Synaptotagmin 1 is necessary for the $\mathrm{Ca} 2+$ dependence of clathrin-mediated endocytosis. $J$ Neurosci (2012) 32:3778-85. doi:10. 1523/JNEUROSCI.3540-11.2012

50. Hunter A, Phillips JH. The recycling of a secretory granule membrane protein. Exp Cell Res (1989) 182:445-60. doi:10.1016/00144827(89)90249-8

51. Hurtley SM. Recycling of a secretory granule membrane protein after stimulated secretion. J Cell Sci (1993) 106(Pt 2): 649-55.
52. Benedeczky I, Somogyi P. Cytochemical localization of exogenous peroxidase in adrenal medullary cells of hamster. Acta Biol Acad Sci Hung (1978) 29:155-63.

53. Patzak A, Aunis D, Langley K. Membrane recycling after exocytosis: an ultrastructural study of cultured chromaffin cells. Exp Cell Res (1987) 171:346-56. doi:10.1016 0014-4827(87)90167-4

54. Perez Bay AE, Ibanez LI Marengo FD. Rapid recovery of releasable vesicles and formation of nonreleasable endosomes follow intense exocytosis in chromaffin cells. Am J Physiol Cell Physiol (2007) 293:C1509-22. doi:10.1152/ajpcell.00632.2006

55. Perez Bay AE, Belingheri AV, Alvarez YD, Marengo FD. Membrane cycling after the excess retrieval mode of rapid endocytosis in mouse chromaffin cells. Acta Physiol (Oxf) (2012) 204:403-18. doi:10.1111/j.1748-1716.2011. 02340.x

56. Opazo F, Punge A, Buckers J, Hoopmann P, Kastrup L, Hell SW, et al. Limited intermixing of synaptic vesicle components upon vesicle recycling. Traffic (2010) 11:800-12. doi:10.1111/j. 1600-0854.2010.01058.x

57. Opazo F, Rizzoli SO. The fate of synaptic vesicle components upon fusion. Commun Integr Biol (2010) 3:427-9. doi:10.4161/cib.3.5.12132

Conflict of Interest Statement: The authors declare that the research was conducted in the absence of any commercial or financial relationships that could be construed as a potential conflict of interest.

Received: 10 July 2013; accepted: 13 September 2013; published online: 02 October 2013.

Citation: Houy S, Croisé P, Gubar O, Chasserot-Golaz S, Tryoen-Tóth P, Bailly $Y$, Ory S, Bader $M-F$ and Gasman $S$ (2013) Exocytosis and endocytosis in neuroendocrine cells: inseparable membranes! Front. Endocrinol. 4:135. doi 10.3389/fendo.2013.00135

This article was submitted to Neuroendocrine Science, a section of the journal Frontiers in Endocrinology.

Copyright (C) 2013 Houy, Croisé, Gubar, Chasserot-Golaz, Tryoen-Tóth, Bailly, Ory, Bader and Gasman. This is an openaccess article distributed under the term of the Creative Commons Attribution License (CC BY). The use, distribution or reproduction in other forums is permitted, provided the original author(s) or licensor are credited and that the original publication in this journal is cited, in accordance with accepted academic practice. No use, distribution or reproduction is permitted which does not comply with these terms. 